\title{
Corrosion Inhibition of Mild Steel Using Brij-30
}

\author{
A.K. Dubey ${ }^{\text {a),* }}$ and G. Singh ${ }^{\text {b) }}$ \\ ${ }^{a}$ Polymer \& Soft Material Section (PSMS), National Physical Laboratory (NPL), Dr. K.S. \\ Krishnan Marg, New Delhi-110012, India. \\ ${ }^{\boldsymbol{b}}$ Corrosion Research Laboratory, Department of Chemistry, University of Delhi-1 10007, India.
}

Received 12 January 2006; accepted 24 May 2006

\begin{abstract}
The corrosion inhibition of mild steel in one normal sulphuric acid solution by brij-30 has been studied in relation to the concentration of the inhibitor as well as the temperature using electrochemical polarization (galvanostatic and potentiostatic) techniques. The results were supplemented with scanning electron microscopy and infra-red spectroscopy. All the methods employed are in reasonable agreement. There is no particular relationship of inhibition with concentration and temperatures. The thermodynamic functions of dissolution and adsorption processes were calculated from experimental polarization data and the interpretation of the results is given. Adsorption of Brij-30 was found to follow the Langmuir's adsorption isotherm. Brij-30 is a mixed type of inhibitor.
\end{abstract}

Keywords: brij-30, corrosion inhibitors, mild steel, $\mathrm{H}_{2} \mathrm{SO}_{4}$, adsorption process, SEM, IR spectra.

\section{Introduction}

Corrosion is a fundamental process playing an important role in economics and safety, particularly for metals. The use of inhibitors is one of the most practical methods for protection against corrosion, especially in acidic media [1]. The use of corrosion inhibitors has considerably increased in recent years due to increase awareness of corrosion worldwide. Inhibitors play an important role in controlling corrosion of metals [2]. It has been observed that the adsorption mainly depends on the presence of electrons and heteroatom, which induce greater adsorption of the inhibitor molecules onto the surface of the mild steel [3].The investigation of the inhibition of corrosion of mild steel is matter of high theoretical as well as practical interest. So, the inhibition efficiency of organic compounds depends on the structure of the inhibitor, the characteristics of the environment and the mode of interaction with the metal surface [4]. According to Balezin [5] every corrosion inhibitor, should: (a) be capable of establishing a stable bond with the metal surface in a given environment of a certain range of acidity and pressure and (b) create an impenetrable layer for corroding ions.

\footnotetext{
* Corresponding author. E-mail address: dubey_delhi@rediffmail.com
} 
The aim of this work is to study the inhibiting effect of brij-30 on mild steel in one normal sulphuric acid solution. Galvanostatic and potentiostatic polarizations were done. The effects of inhibitor concentration at different temperatures were studied. The results were supplemented by SEM and IR studies.

\section{Experimental}

\section{Organic compound}

Brij-30 used as the inhibitor. The molecular formula of brij-30 is $\mathrm{C}_{12}$ $\mathrm{H}_{25}\left(\mathrm{OCH}_{2} \mathrm{CH}_{2}\right)_{\mathrm{n}} \mathrm{OH}$, being four the value of $\mathrm{n}$. Brij-30 was produced from Merck -Schuchardt and was used without further purification.

\section{Chemical composition of mild steel}

\section{Materials}

Mild steel refers to low carbon steel, which is usually used for structural applications. With too little carbon content to through harden, it is weldable, which expands the possible applications. The experiments were performed with cold rolled mild steel specimen. Mild steel coupons of chemical composition $(\mathrm{C}=0.20 \%, \mathrm{Mn}=.1 .00 \%, \mathrm{Si}=0.05 \%, \mathrm{~S}=0.025 \%, \mathrm{P}=0.25 \%$ and $\mathrm{Fe}=98 \%)$ have been used.

\section{Solutions}

The aggressive solutions were made of $\mathrm{AR}$ grade $\mathrm{H}_{2} \mathrm{SO}_{4}$. One normal concentration of acid was prepared using doubled distilled water. The concentrations of the inhibitor employed were $10^{-8} \mathrm{M}, 10^{-6} \mathrm{M}$ and $10^{-4} \mathrm{M}$.

\section{Electrodes}

\section{Working electrode}

Design of working electrodes (WE) is diverse. Most commons in experiments are to study mechanism and kinetics in the laboratory. An essential feature is that the electrode should not react chemically with the solvent or solution components. It is desirable to have an even current and potential distribution and hence for cell to be designed, so that all points on working electrode surface are geometrically equivalent with respect to the secondary electrode.

\section{Reference electrode}

The role of the reference electrode (RE) is to provide a fixed potential which does not vary during the experiments. The RE serves dual purposes of providing a thermodynamic reference and also isolating WE from the system.

\section{Luggin capillary}

The luggin capillary in a laboratory cell is made from glass. It is generally filled with the test solution. The luggin holds the reference electrode. The tip of the luggin capillary near the working electrode is open to the test solution. The reference electrode senses the solution potential at this open tip. Note that the luggin tip is significantly smaller than the reference electrode itself. The luggin capillary allows sensing of the solution potential close to the working electrode 
without the adverse effects that occur when the large reference electrode is placed near the working electrode. A luggin capillary can be used to bring the potential measuring point in close proximity to a working electrode under investigation. Such a device can be made of any material provided it is inert to the electrolytic environment. It basically consists of a bent tube with a large enough opening to accommodate a reference electrode and a usually much smaller opening only large enough to insure diffusion movement of the electrolyte. The device minimizes any iR drop in the electrolyte associated with the passage of current in an electrochemical cell.

\section{Auxiliary electrode (counter electrode)}

The purpose of the counter electrode (CE) is to supply the current required by the working electrode without limiting the measured response of the cell. It is essential that the electrode process is decomposition of the electrolyte, so that the current flows readily without the need for a large over potential.

\section{Surface treatments of working electrode}

The surfaces of carbon steel specimens were abraded successively by different grade of metallographic emery papers until the surfaces appear free from scratches and other apparent defects, then degreased in hot acetone, washed with bi-distilled water and finally dried. The surface treatment was carried out immediately before each experiment of corrosion tests [7].

\section{Corrosion measurements}

Open circuit potential measurements

The potential of mild steel electrodes in produced $1 \mathrm{~N} \mathrm{H}_{2} \mathrm{SO}_{4}$ was measured against saturated calomel electrode in absence and presence of various concentrations of the inhibitor at the temperatures $298 \mathrm{~K}, 308 \mathrm{~K}, 318 \mathrm{~K}$ and 328 K. All measurements were carried out using the type (DM 301 Multi-tester) until the steady state potentials are established. The steady state represents an equilibrium state at which $\mathrm{I}_{\mathrm{ox}}$ is equal to $\mathrm{I}_{\mathrm{red}}$.

\section{Galvanostatic polarization measurements}

The galvanostat is the simplest way to obtain a constant current in order to apply a voltage from low output impedance voltage sources across a larger resistor in series with the cell.

The electrochemical studies were performed in a three electrodes Pyrex glass vessel converter with platinum electrode as counter electrode, saturated calomel electrode (SCE) as reference electrode and the mild steel coupon as working electrode.

The reference electrode coupled to a luggin capillary whose tip was located between the working electrode and the auxiliary electrode (counter electrode). The three necked glass vessel, containing $150 \mathrm{~mL}$ of the electrolyte with and without different concentrated solutions of inhibitor in $1 \mathrm{~N} \mathrm{H}_{2} \mathrm{SO}_{4}$.

The polarization studies were carried out in unstirred solutions, using the galvanostat. In the galavanostatic polarization studies we did cathodic and anodic 
polarization with and without different concentrations of inhibitor at different temperatures. The corrosion inhibition efficiency was calculated using the equation:

$$
\text { Inhibition efficiency }(\mathrm{I} \%)=\mathrm{i}_{0}-\mathrm{i} / \mathrm{i}_{0} \times 100
$$

where $i_{0}$ is the current density in the absence of additive in solution and $i$ is the current density in the presence of additive in the solution.

\section{Potentiostatic polarization measurements}

The potentiostat is a device for controlling the potential between $\mathrm{RE}$ and $\mathrm{WE}$ at a fixed and selected potential. The device is simply a voltage follower maintaining the output voltage between reference electrode (RE) and working electrode (WE) at the programming potential. WE have a potential relative to $\mathrm{RE}$, so that the input voltage is inverted in the cell. The polarization studies were carried out in unstirred solutions, using the potentiostat. The steady state polarization was done by potentiostat by applying $20 \mathrm{mV}$ increment after every minute and corresponding current values were recorded one minute after the potential was applied. The anodic polarization experiments were repeated for a number of times for each set and the reproducible data have been recorded.

\section{Scanning electron microscopy}

Polished mild steel specimens were tested in minimum and maximum inhibitor solutions in one normal sulphuric acid at room temperature for 24 hours. Then they were washed with distilled water, dried in dessicator and therefore subjected to scanning electron microscopic examination. An electron scanning microscope, JEOL 840 SEM was used.

\section{Infra-red spectroscopy}

The saturated solution of inhibitor was prepared in chloroform. In this solution we added small quantity of silica gel. A small quantity of dry solid obtained was as such subjected to FTIR analysis. Spectrum was recorded by using Elmer Infra - red spectroscope, IT 137.

\section{Results and discussion \\ Open circuit potential measurements}

The electrochemical behaviour of mild steel in $1 \mathrm{~N} \mathrm{H}_{2} \mathrm{SO}_{4}$ was studied on the basis of the change in corrosion potentials $\left(\mathrm{E}_{\text {corr }}\right)$ with time. It is seen that in absence of the inhibitor molecules, the open circuit potential tends from the moment of immersion towards more negative value. This behaviour represents the break down of the pre-immersion, air formed oxide film on the mild steel surface. In the presence of different concentrations of the inhibitor the steady state potentials of the working electrodes were shifted towards more positive values, denoting passivation of the mild steel [8]. 


\section{Galvanostatic polarization measurements}

The cathodic and anodic polarization curves for these solutions with and without any inhibitor concentrations at $298 \mathrm{~K}, 308 \mathrm{~K}, 318 \mathrm{~K}$ and at $328 \mathrm{~K}$ are plotted. Logarithms of current densities have been plotted against the corresponding potentials.

From these graphs we obtained the values of corrosion potential $\left(\mathrm{E}_{\mathrm{corr}}\right)$, corrosion current $\left(\log i_{\text {corr }}\right)$, anodic Tafel region $\left(b_{a}\right)$, cathodic Tafel region $\left(b_{c}\right)$, corrosion inhibition efficiency (I \%) and surface coverage $(\theta)$. These values are mentioned in table 1. The one graph obtained at $298 \mathrm{~K}$ is given in the Fig.1.

There was no shift observed in the open circuit potential values which indicates that brij-30 behaves as a mixed inhibitor at temperatures viz. $318 \mathrm{~K}, 328 \mathrm{~K}$, except 298 and $308 \mathrm{~K}$. Therefore, at the first instance the adsorption is through the ion pair formation. A small variation of the inhibitor concentrations causes a considerable reduction of corrosion current and to some extent in corrosion potentials. At lower concentrations of brij-30, the change of corrosion potentials from that in the uninhibited solutions is negligible while at lower temperature at $298 \mathrm{~K}$ and $308 \mathrm{~K}$ only slight changes towards anodic direction are noticeable.

The effect of the concentration of brij-30 on corrosion current at different temperatures is quite apparent from table 1. From all galvanosatic polarizations curves, it is seen that cathodic partial process is governed by hydrogen evolution reduction and by reaction of dissolved oxygen. The trend in cathodic Tafel slope values at all temperatures and concentration is seen to be very irregular, indicating thereby that many mechanisms are taking part in corrosion inhibitions being not only the adsorption effect. The lower values of Tafel slopes at higher temperatures indicate higher hydrogen evolution as well as lower hydrogen inclusion in the metal species.

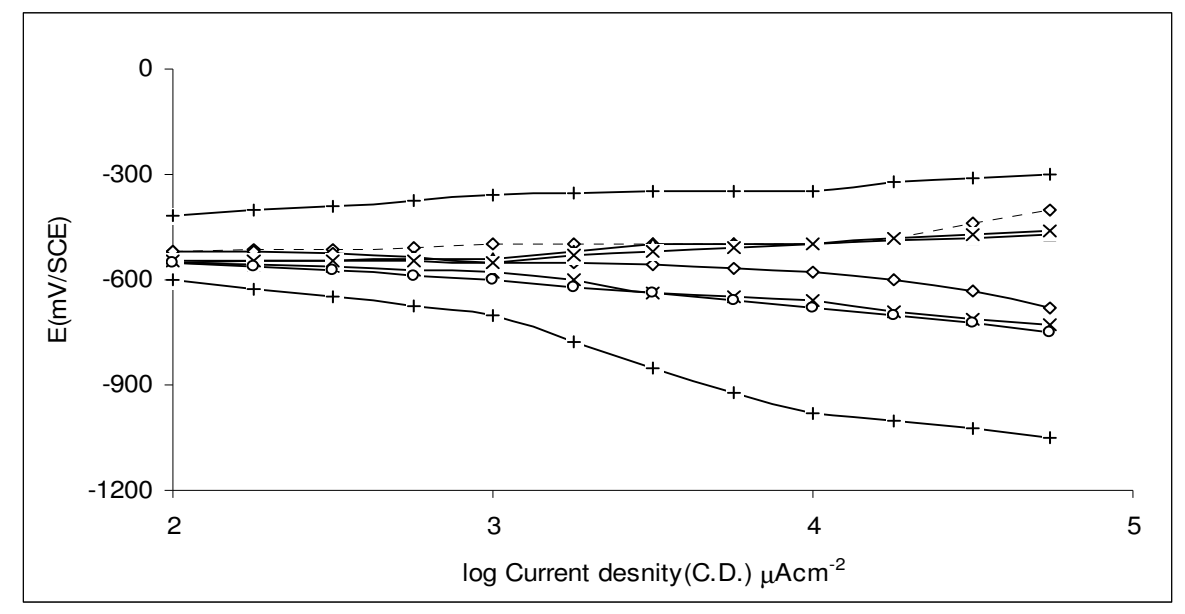

Figure 1. Galvanostatic polarization curves of mild steel in one normal solution containing different concentrations of brij-30, where $\Delta$ denotes are for $1 \mathrm{~N} \mathrm{H}_{2} \mathrm{SO}_{4}$, denotes for $10^{-8} \mathrm{M}$ brij-30 solution, denotes + for $10^{-6} \mathrm{M}$ brij-30 solution, $\mathrm{x}$ denotes for $10^{-4} \mathrm{M}$ brij-30 solution. 
Table 1. Corrosion electrochemical parameters for mild steel grade IS-226 in $1 \mathrm{~N}$ $\mathrm{H}_{2} \mathrm{SO}_{4}$ in the absence and in the presence of brij-30 as additive.

\begin{tabular}{|c|c|c|c|c|c|c|c|c|}
\hline $\mathrm{T}(\mathrm{K})$ & Conc. $(\mathrm{M})$ & $\mathrm{E}_{\text {corr }}(\mathrm{mV})$ & $\begin{array}{c}\log \mathrm{i}_{\text {corr }} \\
\left.\mathrm{mA} / \mathrm{cm}^{2}\right)\end{array}$ & $\mathrm{b}_{\mathrm{c}}(\mathrm{mV} / \mathrm{dec})$ & $\mathrm{b}_{\mathrm{a}}(\mathrm{mV} / \mathrm{dec})$ & $\mathrm{I} \%$ & $\theta$ & $1 / 1-\theta$ \\
\hline \multirow{4}{*}{298} & 0 & 490 & 3.00 & 80 & 35 & 0 & 0 & 0 \\
\cline { 2 - 9 } & $10^{-6}$ & 560 & 2.10 & 92 & 68 & 87.5 & 0.875 & 7.00 \\
\cline { 2 - 9 } & $10^{-4}$ & 568 & 2.24 & 84 & 76 & 82.7 & 0.827 & 4.78 \\
\cline { 2 - 9 } & $10^{-2}$ & 568 & 2.50 & 270 & 60 & 68.4 & 0.684 & 2.16 \\
\hline \multirow{4}{*}{308} & 0 & 520 & 3.00 & 115 & 85 & 0 & 0 & 0 \\
\cline { 2 - 9 } & $10^{-6}$ & 540 & 2.70 & 83 & 63 & 50.0 & 0.500 & 1.00 \\
\cline { 2 - 9 } & $10^{-4}$ & 540 & 2.60 & 54 & 36 & 50.0 & 0.500 & 1.00 \\
\cline { 2 - 9 } & $10^{-2}$ & 520 & 1.60 & 144 & 54 & 96.0 & $0.96-$ & 24.00 \\
\hline 318 & 0 & 520 & 3.12 & 125 & 80 & 0 & 0 & 0 \\
\cline { 2 - 9 } & $10^{-6}$ & 550 & 2.57 & 95 & 58 & 71.8 & 0.818 & 2.54 \\
\cline { 2 - 9 } & $10^{-4}$ & 550 & 2.52 & 109 & 75 & 74.9 & 0.749 & 2.98 \\
\cline { 2 - 9 } & $10^{-2}$ & 544 & 2.12 & 161 & 32 & 90.0 & 0.900 & 9.00 \\
\hline 328 & 0 & 500 & 3.00 & 165 & 276 & 0 & 0 & 0 \\
\cline { 2 - 9 } & $10^{-6}$ & 498 & 2.68 & 237 & 107 & 52.0 & 0.522 & 1.09 \\
\cline { 2 - 9 } & $10^{-4}$ & 524 & 1.90 & 200 & 179 & 92.0 & 0.921 & 11.60 \\
\cline { 2 - 9 } & $10^{-2}$ & 450 & 2.18 & 179 & 107 & 84.0 & 0.842 & 5.32 \\
\hline
\end{tabular}

Very little change in the corrosion potentials suggests that brij-30 at higher temperature controls hydrogen evolution, oxygen reduction as well as the iron dissolution reactions. The inhibitor at higher concentrations, of course, exerts a greater influence on the cathodic process than on that of the anodic process.

The relationship between organic adsorption and hydrogen evolution on the mild steel is still in the early state of understanding. In the case of mild steel this relationship is more complicated by hydrogen permeation into the metal.

The relative importance of each effect may depend on the surface species of the inhibitor.

During metal dissolution, metal oxide reaction and metal hydroxide reaction start the chemical association of brij-30 molecules, with the metal surface through the oxygen ion pair of electron interaction turning to chemical reaction and probably, forming intermediate species $(\mathrm{M}-\mathrm{In})_{\mathrm{ads}}$ or $(\mathrm{M}-\mathrm{In}-\mathrm{OH})_{\mathrm{ads}}$ or $(\mathrm{M}-\mathrm{H}-\mathrm{In})_{\mathrm{ads}}$ and thereby resulting in irregular slopes.

The peculiar behaviour of brij-30 at higher temperatures may be thus due to joint effects of reactions of the inhibitor with electrode surface leading to chemical associations. Under the experimental conditions chosen, it seems plausible to conclude that brij-30 affect the corrosion of iron in acidic media in form of protonated organic molecule and the prevailing inhibitor effect is a mixed one, affecting both the cathodic and anodic reactions. At all temperatures it is seen that inhibition is more or less equal for all similar concentrations. This inhibitor shows a very peculiar behaviour in the sense that with increase in concentration, it is not seen substantial reduction in $i_{\text {corr }}$. At higher temperature the gap between adsorption and desorption becomes shorter and therefore more molecules of 
additive are needed to have higher surface coverage. Therefore with increase in temperature I \% increases but this variation is not very significant.

\section{Effect of temperature and adsorption isotherm}

In order to study the effect of temperature on corrosion inhibition of mild steel in the acid reaction and to determine the activation energy of the corrosion process, the galvonostatic polarization studies were done at various temperatures (298 K$328 \mathrm{~K}$ ) in the absence and in the presence of brij-30 at different concentrations. The corresponding results were given in table.1. The change of corrosion current with temperature is plotted in the Fig. 2 . We note that the corrosion rate increases with rise of temperature both in inhibited and uninhibited acid solutions.

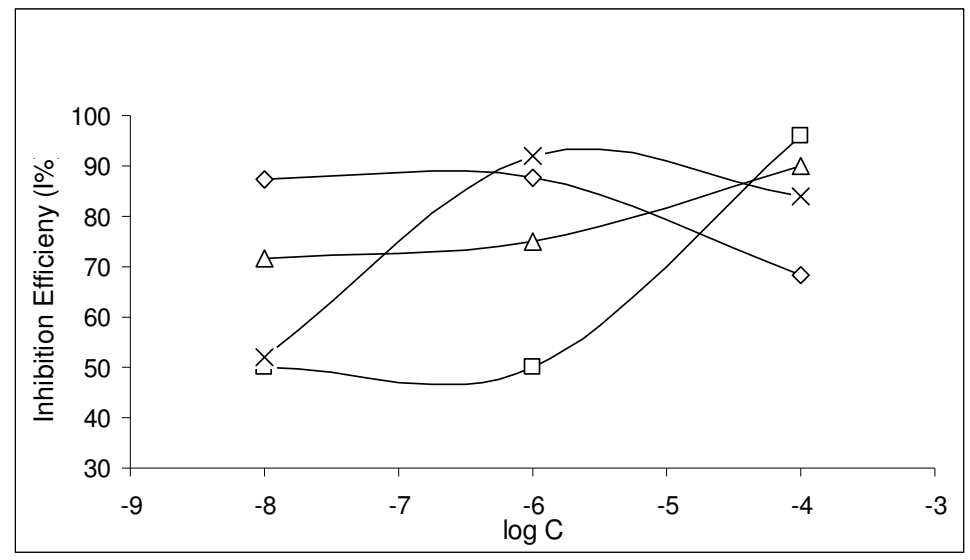

Figure 2. Variation of percentage corrosion inhibition efficiency (I\%) with inhibitor concentration for mild steel coupon in $1 \mathrm{~N} \mathrm{H}_{2} \mathrm{SO}_{4}$ containing various inhibitors at 298 $\mathrm{K}, 308 \mathrm{~K}, 318 \mathrm{~K}$ and $328 \mathrm{~K}$. Where $\diamond$ denotes for $298 \mathrm{~K}, \square$ denotes for $308 \mathrm{~K}, \Delta$ denotes for $318 \mathrm{~K}$, and $\mathrm{X}$ denotes for $328 \mathrm{~K}$.

Fig. 3 shows the change of surface coverage with temperature, whereas fig. 4 shows a plot of $\log (\theta / 1-\theta)$ versus $\log C$, where $\theta$ is the surface covered by inhibitor molecules and $\mathrm{C}$ is the inhibitor concentration in $\mathrm{mol}^{-1}$. The Gibbs energy of adsorption $\left(\Delta \mathrm{G}_{\mathrm{ads}}\right)$ was calculated through the following equation:

$$
\theta / 1-\theta=1 / 55.55 \mathrm{E} \exp \left(-\Delta \mathrm{G}_{\mathrm{ads}} / \mathrm{RT}\right)
$$

The surface coverage value $\theta$ was evaluated using values of inhibition efficiency. The inhibition behaviour of brij-30 at different concentrations and different temperatures assuming change in the mechanism of both the hydrogen evolution reaction and iron dissolution and the degree of coverage $\theta$ can be obtained using the equation

$$
\theta=1-\left(\mathrm{i}_{\text {inh }} / \mathrm{i}_{\text {uninh }}\right)
$$




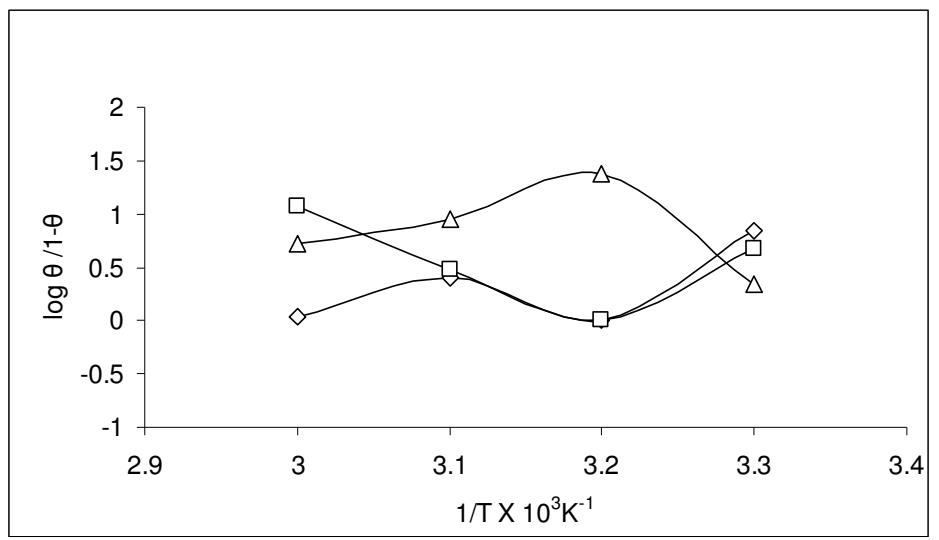

Figure 3. Variation of surface coverage area with temperature $(298 \mathrm{~K}, 308 \mathrm{~K}, 318 \mathrm{~K}$ and $328 \mathrm{~K}$ ) at different inhibitor concentration for mild steel coupon in $1 \mathrm{~N} \mathrm{H}_{2} \mathrm{SO}_{4}$. Where $\Delta$ denotes is for $1 \mathrm{~N} \mathrm{H}_{2} \mathrm{SO}_{4}, \square$ denotes for $10^{-7} \mathrm{M}$ brij-30 solution, denotes + for $10^{-6} \mathrm{M}$ brij-30 solution.

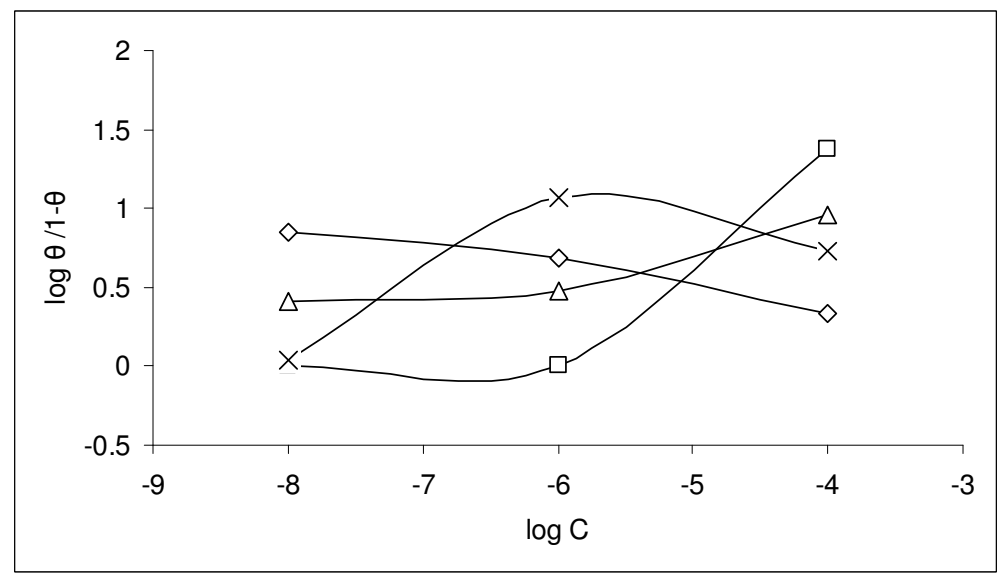

Figure 4. Variation of surface coverage area with inhibitor concentration for mild steel coupon in $1 \mathrm{~N} \mathrm{H}_{2} \mathrm{SO}_{4}$ containing various inhibitors at $298 \mathrm{~K}, 308 \mathrm{~K}, 318 \mathrm{~K}$ and $328 \mathrm{~K}$. Where $\diamond$ denotes for $298 \mathrm{~K}, \square$ denotes for $308 \mathrm{~K}, \Delta$ denotes for $318 \mathrm{~K}, \mathrm{X}$ denotes for $328 \mathrm{~K}$.

It is assumed that inhibitor gives monolayer adsorption coverage at any instant fraction $(\theta)$ of the metal surface in a uniform or random manner and that the free fraction $(\theta)$ of the metals surface $(1-\theta)$ reacts with and as it does in the absence of the inhibitor. The $(1-\theta)$ can be assumed to be equal to $i_{\mathcal{c}} / i_{0}$ and $\theta$ can be calculated readily from the results within a certain range of the inhibitor. The surface coverage due to the progress of adsorption and desorption also changes with temperature. It shows that this inhibitor belongs to the second category of Putilova's classification of inhibitors, which characterized by no effect on the temperature coefficient. This type of inhibitor according to Putilova retards corrosion at ordinary temperature but its efficiency is not reduced considerably at elevated temperature [9]. The series of isotherm obtained over a range of temperature viz, $298 \mathrm{~K}, 308 \mathrm{~K}, 318 \mathrm{~K}$ and $328 \mathrm{~K}$ yielded reasonable values of 
heats of adsorption when the function of $\log (\theta / 1-\theta)$ plotted against the reciprocals of absolute temperature. Plots of inhibited corrosion rates vs. the reciprocal of temperatures for a series of constant inhibitor concentration show that the net activation energy of corrosion process shows irregular trend with concentration of brij-30 in $1 \mathrm{~N} \mathrm{H}_{2} \mathrm{SO}_{4}$ solution. The corrosion behaviour of mild steel surface and surface coverage shows irregular relationship with inhibitor concentration. The values of activation energy $\left(E_{a}\right)$ were calculated using the Arrhenius equation:

$$
E_{a}=-2.3003 \times R \times d\left(\log i_{c}\right) / d(1 / T)
$$

where $\mathrm{R}$ is the universal gas constant and $\mathrm{T}$ is the temperature in Kelvin. The average activation energy of brij-30 is $30.61 \mathrm{kJmol}^{-1}$.

The heat of adsorption $Q$ at different temperatures were calculated from Langmuir's adsorption isotherm equation

$$
\log \theta / 1-\theta=\log \mathrm{A}+\log \mathrm{C}-\mathrm{Q} / \mathrm{RT}
$$

The average heat of adsorption for brij-30 is $50.08 \mathrm{kJmol}^{-1}$. From the value of the adsorption, it can be assumed that brij-30 molecules physiosorbed over mild steel surface by weak forces. Two processes govern this adsorption at particular temperatures (i) ion pair adsorption between protonated molecules and the negatively charged metal surface and (ii) interaction between the lone pair of electrons on nitrogen atom with the vacant orbital of metal atom. This act of inhibition at elevated temperature is hindered by two processes (i) time lag between the processes of adsorption or desorption becoming shorter at higher temperatures and hence the metal is exposed more to acid solution and (ii) the molecular films start acting as proton carrier and the molecules and the film get deprotonated and thus it leads to desorption and therefore this enhanced rate of corrosion results.

From the surface coverage data of the brij-30, it is inferred that the adsorption of the brij-30 on the iron surface inhibits corrosion. Generally, four types of adsorption may take place, involving organic molecule at the metal solution interface [10]:

(i) the electrolytic attraction between charged molecule and the charged metal;

(ii) interaction of unshared electron pairs in the molecules with the metal;

(iii) interaction of $\rho$ electrons with metal, and

(iv) combination of the above points.

Inhibition efficiency depends on several factors, such as the number of adsorption sites and their charge density, molecular size, heat of hydrogenation, mode of interaction with the metal surface and the formation of metallic complexes [11]. Due to adsorption, inhibitor molecules block the reaction sites and reduce the rate of corrosion reaction $[12,13]$. The inhibitor molecules inhibit the corrosion of mild steel by adsorption on the mild steel-solution surface; the adsorption provides the information about the interaction around the adsorbed molecules themselves as well as their interaction with electrode surface. A 
correlation between $\theta$ and concentration of inhibitor in the electrolyte can be represented by the Langmuir's adsorption equation:

$$
\theta=\mathrm{KC}(1+\mathrm{KC})
$$

where $\mathrm{K}$ is a constant of adsorption.

According to Bockris and Drazic, the inhibition mechanism could be explained by $\mathrm{Fe}-(\mathrm{Inh})_{\mathrm{ads}}$ reaction intermediated as below[14]:

$$
\mathrm{Fe}+\mathrm{Inh} \Leftrightarrow(\operatorname{Inh})_{\mathrm{ads}} \Leftrightarrow \mathrm{Fe}^{\mathrm{n}^{+}}+\mathrm{ne}^{-}+\mathrm{Inh}
$$

The adsorbed layer combats the action of sulphuric acid solution and enhances protection of the metal surface $[15,16]$. When there is sufficient $\mathrm{Fe}(\operatorname{Inh}\}_{\text {ads }}$ to cover the metal surface (if the inhibitor concentration was low or the adsorption rate was slow), metal dissolution would take place at sites on the mill steel surface which are free of $\mathrm{Fe}$-(Inh) $)_{\text {ads. }}$ With high inhibitor concentration a compact and coherent inhibitor over layer forms on mild steel surface, reducing chemical attack on the metal. The adsorption of an organic molecule on the surface of the mild steel is regarded as a substitution of adsorption process between the organic compound in the aqueous phase $\left(\operatorname{Org}_{\mathrm{aq}}\right)$ and the water molecules adsorbed on the mild steel surface $\left(\mathrm{H}_{2} \mathrm{O}_{\text {ams }}\right)$

$$
\operatorname{Org}_{\mathrm{aq}}+\mathrm{x} \mathrm{H}_{2} \mathrm{O}_{\mathrm{ams}} \Leftrightarrow \operatorname{Org}{ }_{\mathrm{ams}}+\mathrm{x} \mathrm{H}_{2} \mathrm{O}_{\mathrm{aq}}
$$

where $\mathrm{x}$ is the size ratio, in terms of the number of water molecules replaced by adsorbate molecules. When the equilibrium of the process described in the above equation is reached it is possible to obtain different expression of the adsorption isotherm plots.

\section{Potentiostatic polarization measurements}

A detailed study of steady state potentiostatic polarization behavior of anodic dissolution of mild steel in the presence of brij-30 was made in $1 \mathrm{~N} \mathrm{H}_{2} \mathrm{SO}_{4}$ solution at room temperature $(298 \mathrm{~K})$. The graph between potential and current density is plotted for $1 \mathrm{~N} \mathrm{H}_{2} \mathrm{SO}_{4}, 10^{-8} \mathrm{M}, 10^{-6} \mathrm{M}$ and $10^{-4} \mathrm{M}$ solution of brij-30 plotted in Fig.5 and the values of critical current density ( $\left.i_{\text {crit }}\right)$, passive current $\left(i_{p}\right)$ and passivation potential $\left(\mathrm{E}_{\mathrm{pp}}\right)$ are mentioned in the table 2 . It is seen from table 2 and Fig. 5 that $i_{p}, E_{p p}$ become lower and $i_{c}$ becomes higher on comparison with the dissolution in the absence of the TMAB. Hence it can be concluded that brij30 is a good passivator. $\mathrm{H}_{3} \mathrm{O}, \mathrm{H}_{2} \mathrm{SO}_{4}, \mathrm{SO}_{4}$ and $\mathrm{OH}$ ions present in the solution interfere with formation of resistance layer because of adsorption of brij-30 on the metal surface with the help of already adsorbed anions present in the solution. 


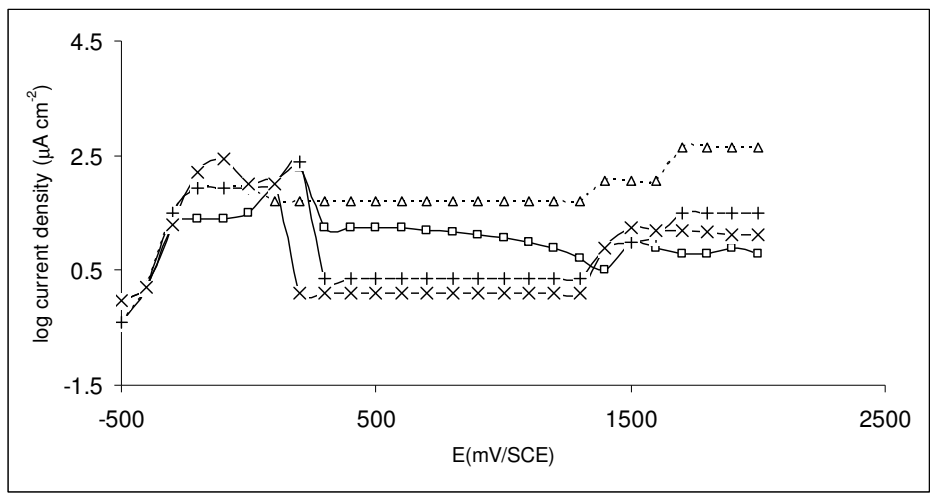

Figure 5. Potentiostatic polarization curves of mild steel in one normal solution containing different concentrations of brij-30. Where $\Delta$ denotes for $1 \mathrm{~N} \mathrm{H}_{2} \mathrm{SO}_{4}, \square$ denotes for $10^{-8} \mathrm{M}$ brij-30 solution, + denotes for $10^{-6} \mathrm{M}$ brij-30 solution, $\mathrm{x}$ denotes for $10^{-4} \mathrm{M}$ brij-30 solution.

Table 2. Passivation data for brij-30 obtained by potentiostatic polarization.

\begin{tabular}{|l|c|c|c|}
\hline Additive & $\begin{array}{c}\text { Critical current density } \\
\mathrm{I}_{\text {cric }} \mathrm{mA} / \mathrm{cm}^{2}\end{array}$ & $\begin{array}{c}\text { Passivation current } \\
\text { density }\left(\mathrm{I}_{\mathrm{p}}\right) \mathrm{mA} / \mathrm{cm}^{2}\end{array}$ & $\begin{array}{c}\text { Ranges of passivation } \\
\text { potential } \mathrm{E}_{\mathrm{pp}}(\mathrm{V})\end{array}$ \\
\hline $1 \mathrm{~N} \mathrm{H}_{2} \mathrm{SO}_{4}$ & 79.4 & 50.1 & $110-1340$ \\
\hline $10^{-8} \mathrm{M}$ & 295 & 12.58 & $405-1343$ \\
\hline $10^{-6} \mathrm{M}$ & 295 & 2.51 & $280-1280$ \\
\hline $10^{-4} \mathrm{M}$ & 263 & 1.41 & $202-1909$ \\
\hline
\end{tabular}

It is commonly accepted that kinetic of iron anodic oxidation in acid depends on the adsorbed intermediates $\mathrm{FeOH}_{\text {ads }}$. An iron anodic oxidation mechanism, which is valid in the presence of inhibitor, could be similar to that discussed by Mc Cafferty and Hackerman and also by Sternberg and Branzoi [17]

$$
\begin{aligned}
& \mathrm{Fe}+\mathrm{H}_{2} \quad \leftrightarrow \mathrm{Fe} . \mathrm{H}_{2} \mathrm{O}_{\text {ads }} \\
& \mathrm{Fe} . \mathrm{H}_{2} \mathrm{O}+\mathrm{X} \leftrightarrow \mathrm{FeOH}^{-}+\mathrm{H}_{2} \mathrm{O} \\
& \text { Fe. } \mathrm{H}_{2 \text { ads }}+\mathrm{X} \leftrightarrow \mathrm{FeX}_{\mathrm{ads}}+\mathrm{H}_{2} \mathrm{O} \\
& \mathrm{FeOH}^{-} \text {ads } \leftrightarrow \mathrm{FeOH}_{\text {ads }}+\mathrm{e}^{-} \\
& \mathrm{FeX}_{\text {ads }} \leftrightarrow \mathrm{FeX}+\mathrm{ads}+\mathrm{e}^{-} \\
& \mathrm{FeOH}_{\text {ads }}+\mathrm{FeX}^{+} \text {ads } \leftrightarrow \mathrm{FeX}_{\text {ads }}+\mathrm{FeOH}^{+} \\
& \mathrm{FeOH}^{+}+\mathrm{H}^{+} \leftrightarrow \mathrm{Fe}^{+}+\mathrm{H}_{2} \mathrm{O}
\end{aligned}
$$

where the species $X$ are the inhibitor molecule, in our case. This mechanism shows that the anodic reaction kinetics is affected by two intermediates: one involving adsorbed hydroxyl $\left(\mathrm{FeOH}_{\mathrm{ads}}\right)$ and the other involving the adsorbed inhibitor molecule $\left(\mathrm{FeX}_{\mathrm{ads}}\right)$. The main effect of the petroleum content on the value of corrosion rate may account for the high effect exerted by the organic inhibitor molecule on the anodic reaction. The rate of anodic dissolution (step 4) depends on the product of step (2), but the two competitive steps (2) and (3) are based on the Fe. $\mathrm{H}_{2} \mathrm{O}_{\text {ads }}$. Displacements of the adsorbed water molecule by the 
species X, can affects on the step (4). Every condition, such as molecular shape or localized partial charges or by another view, strict hindrance of $\mathrm{X}$ molecule to the metal surface, can variegate the above competition. The influence of two solvents on each inhibitor molecule causes dispersion of inhibition ability. This dispersion may accelerate from the adsorption of the inhibitor molecule onto the different metal surface sites having different activation energies for chemisorptions (lattice planes, edges, kinks, dislocations, inhomogeneities, etc.). The passive film on mild steel is a hydrated oxide film having a gel like structure and protons present in the passive film are pulled out by the anodic polarizations. As per Pyun hydrogen is ionized to protons in the passive film due to the anodic character of the passive film. As hydrogen is charged into passive film, the average concentration of protons increases the amount of hydrogen containing species such as $\mathrm{H}_{2} \mathrm{O}$ and $\mathrm{OH}^{-}$in the passive films and with the increase of potential beyond passive ranges the passive films braked to give trans-passive region with evolution of oxygen in this range.

It may be noted that brij-30 forms a passive layer or resistive layer with the help of already adsorbed anions present in the solutions. The cooperative adsorption leads to the formation of the complexes of the types $(\mathrm{M}-\mathrm{In}-\mathrm{OH})_{\text {ads }}$ or $(\mathrm{M}-\mathrm{OH}-$ In $)_{\text {ads }}$ or $(\mathrm{M}-\mathrm{In}-\mathrm{A})_{\mathrm{ads}}$, where $\mathrm{A}$ is any of the already adsorbed anions on the metal surface which gives large potential regions.

\section{Scanning electron microscopy}

In the present work SEM was operated at $10 \mathrm{KV}$, since the secondary electrons emanate from a depth of about $10 \AA$ or less from corroded surface. Fig. 6 (A) shows the micrographs by SEM of the unexposed surface of the uncorroded surface of mild steel which is found to be absolutely free from any noticeable defect such as cracks and pits. Polishing scratches are also visible. Fig. 6 (B, C, and D) show micrographs by SEM of mild steel specimens exposed in $1 \mathrm{~N}$ $\mathrm{H}_{2} \mathrm{SO}_{4}, 10^{-7} \mathrm{M}$ brij-30, $10^{-5} \mathrm{M}$ brij-30, and $10^{-3} \mathrm{M}$ brij-30 solutions at a magnification of 2000 .

Uniform corrosion was observed. Flakes which show corrosion products are observed in the micrographs. It is quite apparent from the micrographs the uniform products like metal hydrides, and their oxides are also visible. The electron micrograph reveals that the surface was strongly damaged owing to corrosion in absence of the inhibitor, but in the presence of the inhibitor there is a much smaller damage on the surface. This is attributed to the formation of a good protective film on the carbon steel surface. On comparison brij-30 acts as good inhibitor at higher concentration. The extent of inhibitor is reduced considerably in the presence of smaller concentrations of Brij-30.

\section{Infra-red spectroscopy}

Silica gel was specially chosen because finally divided silica gels crystals have larger surface area for adsorption of organic molecules. Thus sufficient adsorbed material can be included in the sample to yield a spectrum of moderate intensity. Further with such finally divided materials radiations lost by scattering are not large, especially at frequencies below $3000 \mathrm{~cm}^{-1}$. The various peaks in the spectra 
of silica gel, pure brij-30 and brij-30 adsorbed over silica gel are given in the Figs. 7 and 8 . The peaks have been tabulated in the table 3 .
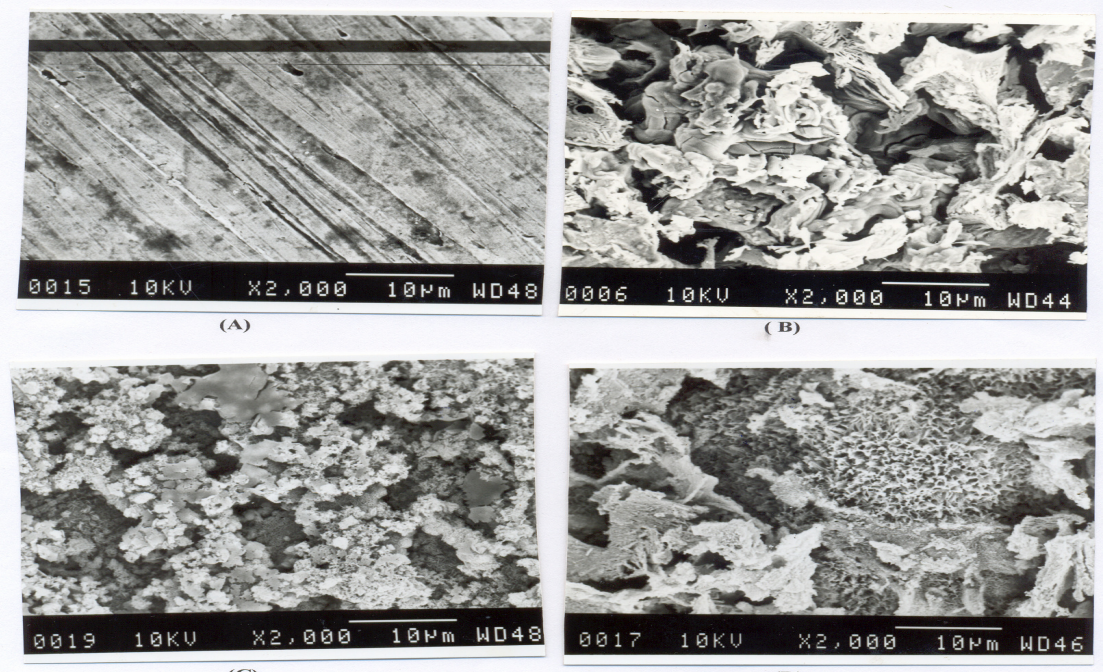

Figure 6. Scanning electron micrographs of mild steel samples (at 2000 magnification): (A) after polishing, (B) after immersion in $1 \mathrm{~N} \mathrm{H}_{2} \mathrm{SO}_{4}$ for 24 hours, (C) after immersion in $10^{-4} \mathrm{M}$ brij-30 solution for 24 hours, (D) after immersion in $10^{-8} \mathrm{M}$ brij30 solution for 24 hours.

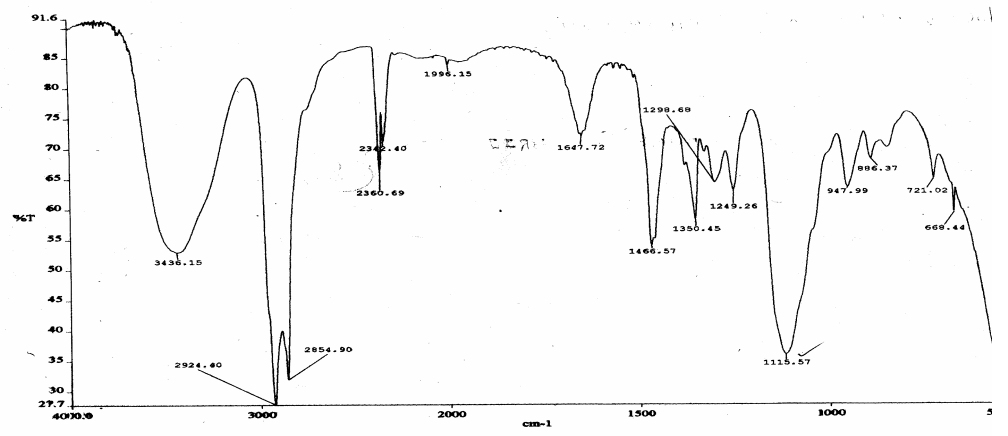

Figure 7. Infra-red spectra (the graph between $\%$ transmittance and frequencies) of brij30 .

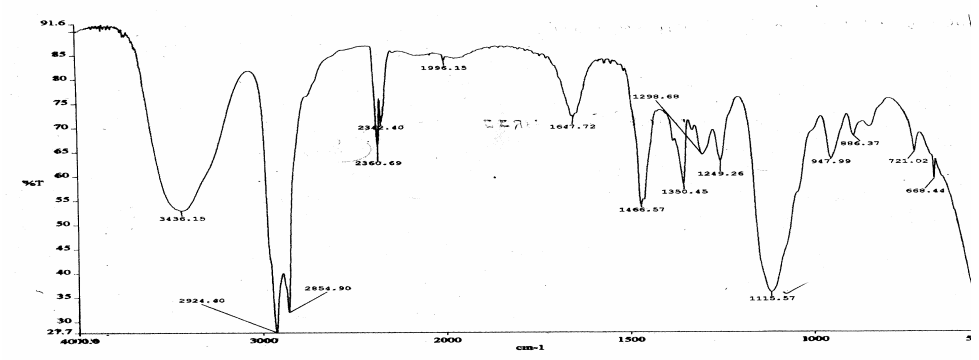

Figure 8. Infra-red spectra (the graph between \% transmittance and frequencies) of brij30 adsorbed on silica gel. 
Table 3. Infra-red spectroscopic data of brij-30.

\begin{tabular}{|l|c|c|c|c|c|c|c|c|}
\hline Inhibitor & $\begin{array}{c}\mathrm{C}-\mathrm{H} \\
\left(\mathrm{cm}^{-1}\right)\end{array}$ & $\begin{array}{c}\mathrm{C}-\mathrm{C} \\
\left(\mathrm{cm}^{-1}\right)\end{array}$ & $\begin{array}{c}\mathrm{C}-\mathrm{O} \\
\left(\mathrm{cm}^{-1}\right)\end{array}$ & $\begin{array}{c}\mathrm{C}-\mathrm{OH} \\
\left(\mathrm{cm}^{-1}\right)\end{array}$ & $\begin{array}{c}\mathrm{N}-\mathrm{C} \\
\left(\mathrm{cm}^{-1}\right)\end{array}$ & $\begin{array}{c}\mathrm{N}-\mathrm{H} \\
\left(\mathrm{cm}^{-1}\right)\end{array}$ & $\begin{array}{c}\mathrm{C}=\mathrm{C} \\
\left(\mathrm{cm}^{-1}\right)\end{array}$ & $\begin{array}{c}\mathrm{N}-\mathrm{H} \\
\text { Deformation } \\
\left(\mathrm{cm}^{-1}\right)\end{array}$ \\
\hline brij-30 & 2923.40 & 1249.26 & 1115.57 & & - & - & - & - \\
\hline brij-30 ads & 2923.94 & - & 1111.44 & & - & - & - & - \\
\hline
\end{tabular}

In the spectra of brij-30, it is seen that C-C peaks at 1249.26 disappear completely while that $\mathrm{C}-\mathrm{O}$ and $\mathrm{C}-\mathrm{OH}$ is shifted to some higher frequencies, proving that the adsorption of these is taking place through $\mathrm{C}-\mathrm{C}$ and $\mathrm{C}-\mathrm{OH}$ bonds.

\section{Conclusions}

1. Brij-30 is very effective corrosion inhibitor of mild steel in acidic medium, particularly at $298 \mathrm{~K}$ and at higher concentrations.

2. The inhibition efficiency increases with inceasing the concentration, whereas its inhibition efficiency almost remains the same with increasing the temperature.

3. This is a mixed type inhibitor.

4. It mainly acts by blocking the active sites on the cathodic and anodic regions.

\section{References}

1. Xianghong Li and Guannan Mu, Applied Surface Science 252-5 (2005) 1254.

2. M.A. Quraishi, R.Sardar, Materials Chemistry and Physics 71-3 (2001) 309.

3. M.M. Osman, R.A. El-Ghazawy and A.M. Al-Sabagh, Materials Chemistry and Physics 80 (2003) 55.

4. C. Jeyaprabha, S. Sathiyanarayan, G. Venkatchari, Appl. Surf. Sci. 246 (2005) 108.

5. K.L. Vasanth, NACE, National Association of Corrosion Engineers, Paper\# 233, Corrosion 96.

6. M.A. Migahed, Prog. In. Org. Coat. 54 (2005) 92.

7. J.M. Abd El-Kader, A.A. El-Warraky, A.M. Abd El-aziz, Br. Corros. J. 3302 (1998) 139.

8. I.N. Putilova, S.A. Balezin and V.P. Barannik, Met. Corros. Inhibitors, Pergamm Press, N.Y. (1960) 31.

9. D. Schweinsberg, G. George, A. Nanayakkara, D. Steiner, Corr.Sci.28(1988),55

10. A. Fouda, M. Moussa, P. Taha and E.L. Neanaa, Corr. Sci. 26 (1986) 719.

11. N. Hackerman, E. Snavely Jr. and J.S. Payne, J. Electrochem. Soc. 113 (1966) 651.

12. T. Murekewa, N. Hackerman, Corr. Sci. 4 (987) 051.

13. J.O' M. Bockris and Drazic, Electrochim. Acta 7 (1962) 293.

14. G. Moretti, G. Quartarone, A. Tatsan and A. Zingales, Werkst. Korros. 45 (1994) 5 . 
15. M.A. Quraishi, J. Rawat and M. Ajmal, J. Appl. Electrochem. 30 (2000) 745.

16. H. Ashassi-Sorkhabi and S.A. Nabavi-Amri, Acta Chim. Slov. 47 (2000) 512. 